\title{
The Effects of Thickness On Frequency Values for Rotating Circular Shells
}

\author{
Kadir Mercan ${ }^{1}$, Çiğdem Demir ${ }^{1}$, Hakan Ersoy ${ }^{2}$, Ömer Civalek $^{1}$ \\ ${ }^{1}$ Akdeniz University, Faculty of Engineering, Civil Engineering Dept., Division of Mechanics \\ ${ }^{2}$ Akdeniz University, Faculty of Engineering, Mechanical Engineering Dept., Division of Mechanics \\ Antalya-TURKIYE \\ "E-mail address: civalek@yahoo.com
}

Received date: April 2016

Accepted date: May 2016

\begin{abstract}
The aim of the present paper is to investigate effect of thickness on frequency. For this, free vibration analysis of circular shells is made via ANSYS and numerical method. Discrete singular convolution (DSC) and differential quadrature methods have been proposed for numerical solution of vibration problem. The formulations are based on the Love's first approximation shell. The performance of the present methodology is also discussed.
\end{abstract}

Keywords: Discrete singular convolution, ANSYS, free vibration, frequencies, cylindrical shells.

\section{Introduction}

Cylindrical shells are widely used in many engineering applications such as mechanical, civil and aerospace engineering. Rotating circular shell structures are increasingly being used in many engineering applications like aviation, rocketry, missiles, chemical, aero-space, civil and mechanical industries. Thus, frequencies and mode shapes of such structures are important in the design of systems [1-4]. As a consequence, a number of analytical and numerical methods have been also studied on the vibration analysis of circular cylindrical shells [5-12]. In this study, free vibration analysis of rotating and non-rotating cylindrical shells is investigated by the method of DSC and DQ approaches. Also, the ANSYS program has been used for some analyses.

\section{Fundamental equations}

Consider a cylindrical shell rotating about its symmetrical and horizontal axis at an angular velocity $\omega$ as shown in Figure 1. The thickness of the shell, and cone length are denoted by $h$ and $L$, respectively. The cylindrical shell is referred to a coordinate system $(x, \theta$, z) as shown in Figure 1. The components of the deformation of the cylindrical shell with references to this coordinate system are denoted by $u, v, w$ in the $x, \theta$ and $z$ directions, respectively. 


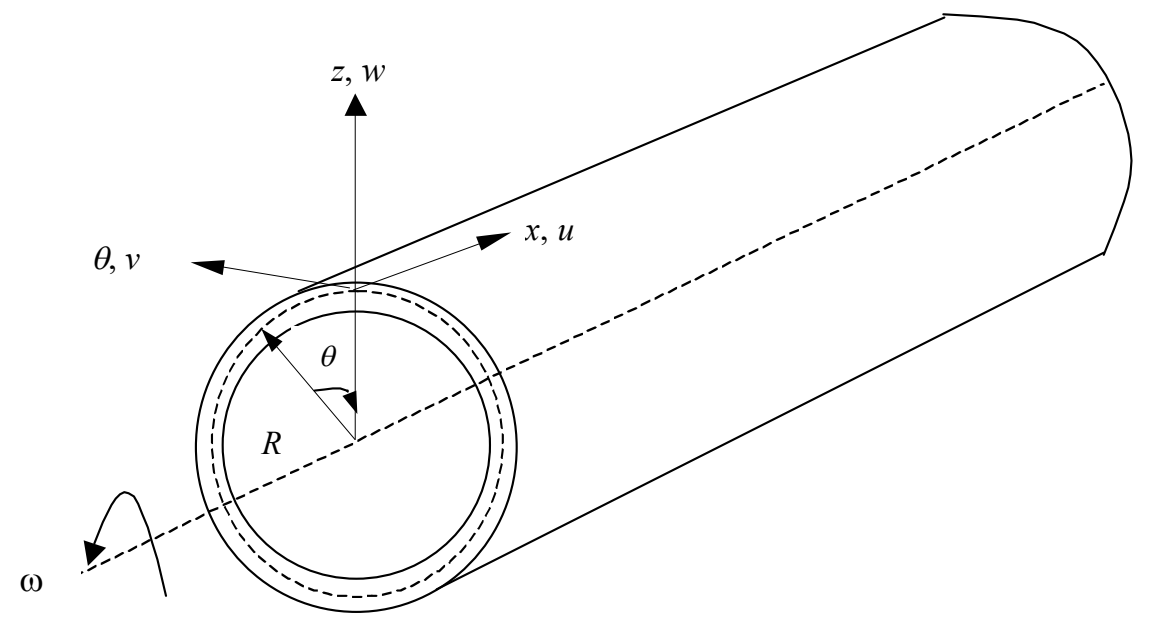

Fig.1. Geometry of a thin rotating cylindrical shell.

Following the Love's first approximation shell theory [12] governing equations for free vibration analysis of cylindrical shells can be given as $[39,40]$;

$$
\begin{gathered}
L_{11} u+L_{12} v+L_{13} w-\rho h \frac{\partial^{2} u}{\partial t^{2}}=0, \\
L_{21} u+L_{22} v+L_{23} w-\rho h \frac{\partial^{2} v}{\partial t^{2}}=0, \\
L_{31} u+L_{32} v+L_{33} w-\rho h \frac{\partial^{2} w}{\partial t^{2}}=0 .
\end{gathered}
$$

where

$$
\begin{gathered}
L_{11}=A_{11} \frac{\partial^{2}}{\partial x^{2}}+\frac{A_{66}}{R^{2}} \frac{\partial^{2}}{\partial \theta^{2}}, \\
L_{12}=\frac{\left(A_{12}+A_{66}\right)}{R} \frac{\partial^{2}}{\partial x \partial \theta}+\frac{\left(B_{12}+2 B_{66}\right)}{R^{2}} \frac{\partial^{2}}{\partial x \partial \theta} \\
L_{13}=\frac{A_{12}}{R} \frac{\partial}{\partial x}-\frac{B_{12}+2 B_{66}}{R^{2}} \frac{\partial^{3}}{\partial x \partial \theta^{2}}-B_{11} \frac{\partial^{3}}{\partial x^{3}} \\
L_{21}=\frac{\left(A_{12}+A_{66}\right)}{R} \frac{\partial^{2}}{\partial x \partial \theta}+\frac{\left(B_{12}+2 B_{66}\right)}{R^{2}} \frac{\partial^{2}}{\partial x \partial \theta}
\end{gathered}
$$




$$
\begin{aligned}
& L_{22}=A_{66}\left[\frac{\partial^{2}}{\partial x^{2}}+\frac{\sin \alpha}{R(x)} \frac{\partial}{\partial x}-\frac{\sin ^{2} \alpha}{R^{2}(x)}\right]+\left[\frac{A_{22}}{R^{2}(x)}+\frac{D_{22} \cos ^{2} \alpha}{R^{4}(x)}\right] \frac{\partial^{2}}{\partial \theta^{2}} \\
& +2 \frac{D_{66} \cos ^{2} \alpha}{R^{2}(x)}\left[\frac{\partial^{2}}{\partial x^{2}}-\frac{2 \sin \alpha}{R(x)} \frac{\partial}{\partial x}+\frac{2 \sin ^{2} \alpha}{R^{2}(x)}\right] \\
& L_{23}=\left(\frac{A_{22} \cos \alpha}{R^{2}(x)}-\frac{4 D_{66} \cos \alpha \sin ^{2} \alpha}{R^{4}(x)}\right) \frac{\partial}{\partial \theta}-\frac{D_{22} \cos \alpha}{R^{4}(x)} \frac{\partial^{3}}{\partial \theta^{4}} \\
& -\frac{\left(D_{22}-4 D_{66}\right) \sin \alpha \cos \alpha}{R^{3}(x)} \frac{\partial^{2}}{\partial x \partial \theta}-\frac{\left(D_{12}+2 D_{66}\right) \cos \alpha}{R^{2}(x)} \frac{\partial^{3}}{\partial x^{2} \partial \theta}, \\
& L_{31}=-A_{12} \frac{\cos \alpha}{R(x)} \frac{\partial}{\partial x}-A_{22} \frac{\sin \alpha \cos \alpha}{R^{2}(x)} \\
& L_{32}=-\left[A_{22} \frac{\cos \alpha}{R^{2}(x)}-\frac{\left(2 D_{12}+2 D_{22}+8 D_{66}\right) \cos \alpha_{\sin ^{2} \alpha}}{R^{4}(x)}\right] \frac{\partial}{\partial \theta} \\
& +D_{22} \frac{\cos \alpha}{R^{4}(x)} \frac{\partial^{3}}{\partial \theta^{4}}+\frac{\left(D_{12}+4 D_{66}\right) \cos \alpha}{R^{2}(x)} \frac{\partial^{3}}{\partial x^{2} \partial \theta} \\
& -\left[\frac{\left(D_{22}+2 D_{12}+8 D_{66}\right) \sin \alpha \cos \alpha}{R^{3}(x)}\right] \frac{\partial^{2}}{\partial x \partial \theta}, \\
& L_{33}=-A_{22} \frac{\cos ^{2} \alpha}{R^{2}(x)}-D_{11} \frac{\partial^{4}}{\partial x^{4}}-\frac{2\left(D_{12}+2 D_{66}\right)}{R^{2}(x)} \frac{\partial^{4}}{\partial x^{2} \partial \theta^{2}}-\frac{D_{22}}{R^{4}(x)} \frac{\partial^{4}}{\partial \theta^{4}} \\
& -\frac{2 D_{11} \sin \alpha}{R(x)} \frac{\partial^{3}}{\partial x^{3}}+\frac{2\left(D_{12}+4 D_{66}\right) \sin \alpha}{\partial x \partial \theta^{2}}+\frac{\partial^{3}}{R^{2}(x)} \frac{D^{2} \alpha}{\partial x^{2}} \\
& -\frac{2\left(D_{12}+\left(D_{22}+4 D_{66}\right) \sin ^{2} \alpha\right.}{R^{4}(x)} \frac{\partial^{2}}{\partial \theta^{2}}-\frac{D_{22} \sin ^{3} \alpha}{R^{2}(x)} \frac{\partial}{\partial x} .
\end{aligned}
$$

\section{Discrete Singular Convolution (DSC)}

The discrete singular convolutions (DSC) algorithm was originally introduced by Wei [13]. Since then, applications of the DSC method to various science and engineering problems have been investigated and their successes have demonstrated the potential of the method as an attractive numerical analysis technique [14-20]. In this paper, details of the DSC 
method are not given; interested readers may refer to the works of [13-17]. Consider a distribution, $T$ and $\eta(t)$ as an element of the space of the test function. A singular convolution can be defined by [15]

$$
F(t)=(T * \eta)(t)=\int_{-\infty}^{\infty} T(t-x) \eta(x) d x
$$

where $T(t-x)$ is a singular kernel. The DSC algorithm can be realized by using many approximation kernels. However, it was shown [21-28] that for many problems, the use of the regularized Shannon kernel (RSK) is very efficient. The RSK is given by [16]

$$
\delta_{\Delta, \sigma}\left(x-x_{k}\right)=\frac{\sin \left[(\pi / \Delta)\left(x-x_{k}\right)\right]}{(\pi / \Delta)\left(x-x_{k}\right)} \exp \left[-\frac{\left(x-x_{k}\right)^{2}}{2 \sigma^{2}}\right] ; \sigma>0
$$

where $\Delta=\pi /(N-1)$ is the grid spacing and $N$ is the number of grid points. The parameter $\sigma$ determines the width of the Gaussian envelope and often varies in association with the grid spacing, i.e., $\sigma=r \mathrm{~h}$. In the DSC method, the function $f(x)$ and its derivatives with respect to the $x$ coordinate at a grid point $x_{i}$ are approximated by a linear sum of discrete values $f\left(x_{\mathrm{k}}\right)$ in a narrow bandwidth $\left[x-x_{\mathrm{M}}, x+x_{\mathrm{M}}\right]$. This can be expressed as [21]

$$
\left.\frac{d^{n} f(x)}{d x^{n}}\right|_{x=x_{i}}=f^{(n)}(x) \approx \sum_{k=-M}^{M} \delta_{\Delta, \sigma}^{(n)}\left(x_{i}-x_{k}\right) f\left(x_{k}\right) ; \quad(n=0,1,2, \ldots,)
$$

where superscript $n$ denotes the $n$ th-order derivative with respect to $x$. Beams, plates and shells have been successfully solved via DSC method by this time [22-38]. Also, some macro and nano structures analyzed by DSC [60,61].

\section{Differential quadrature (DQ) method}

In the DQ method, a partial derivative of a function with respect to a space variable at a discrete point is approximated as a weighted linear sum of the function values at all discrete points in the region of that variable [41-59]. For simplicity, we consider a one-dimensional function $u(x)$ in the $[-1,1]$ domain, and $N$ discrete points. Then the first derivatives at point $i$, at $x=x_{i}$ is given by

$$
u_{x}\left(x_{i}\right)=\left.\frac{\partial u}{\partial x}\right|_{x=x_{i}}=\sum_{j=1}^{N} A_{i j} u\left(x_{j}\right) ; \quad i=1,2, \ldots, N
$$

where $x_{j}$ are the discrete points in the variable domain, $u\left(x_{j}\right)$ are the function values at these points and $A_{i j}$ are the weighting coefficients for the first order derivative attached to these function values. Two methods can possible to determine the weighting coefficients. The first one is to let equation (1) be exact for the test functions

$$
u_{k}(x)=x^{k-1} ; k=1,2, \ldots, N,
$$


which leads to a set of linear algebraic equations

$$
(k-1) x_{i}^{k-2}=\sum_{j=1}^{N} A_{i j} x_{j}^{k-1} ; \text { for } i=1,2, \ldots, N \text { and } k=1,2, \ldots, N
$$

which represents $N$ sets of $N$ linear algebraic equations. Another way to determine the weighting coefficients is to employ harmonic functions, named the harmonic differential quadrature (HDQ). Harmonic differential quadrature has been proposed by Striz et al. [22]. Unlike the DQ that uses the polynomial functions, such as power functions, Lagrange interpolated, and Legendre polynomials as the test functions, HDQ uses harmonic or trigonometric functions as the test functions. Shu and Xue proposed an explicit means of obtaining the weighting coefficients for the HDQ [53]. When the $f(x)$ is approximated by a Fourier series expansion in the form [42-50]

$$
f(x)=c_{0}+\sum_{k=1}^{N / 2}\left(c_{k} \cos \frac{k \pi x}{L}+d_{k} \sin \frac{k \pi x}{L}\right),
$$

and the Lagrange interpolated trigonometric polynomials are taken as [52,53]

$$
h_{k}(x)=\frac{\sin \frac{\left(x-x_{0}\right) \pi}{2} \cdots \sin \frac{\left(x-x_{k-1}\right) \pi}{2} \sin \frac{\left(x-x_{k+1}\right) \pi}{2} \cdots \sin \frac{\left(x-x_{N}\right) \pi}{2}}{\sin \frac{\left(x_{k}-x_{0}\right) \pi}{2} \cdots \sin \frac{\left(x_{k}-x_{k-1}\right) \pi}{2} \sin \frac{\left(x_{k}-x_{k+1}\right) \pi}{2} \cdots \sin \frac{\left(x_{k}-x_{N}\right) \pi}{2}}
$$

for $k=0,1,2, \ldots, N$. According to the HDQ, the weighting coefficients of the first-order derivatives $A_{i j}$ for $i \neq j$ can be obtained by using the following formula:

$$
A_{i j}=\frac{(\pi / 2) P\left(x_{i}\right)}{P\left(x_{j}\right) \sin \left[\left(x_{i}-x_{j}\right) / 2\right] \pi} ; \quad i, j=1,2,3, \ldots, N
$$

where

$$
P\left(x_{i}\right)=\prod_{j=1, j \neq i}^{N} \sin \left(\frac{x_{i}-x_{j}}{2} \pi\right) ; \quad \text { for } \mathrm{j}=1,2,3, \ldots, N
$$

The weighting coefficients of the second-order derivatives $B_{i j}$ for $i \neq j$ can be obtained using the following formula:

$$
B_{i j}=A_{i j}\left[2 A_{i i}^{(1)}-\pi \cot \left(\frac{x_{i}-x_{j}}{2}\right) \pi\right] ; \quad i, j=1,2,3, \ldots, N,
$$


The weighting coefficients of the first-order and second-order derivatives $A_{i j}{ }^{(p)}$ for $i=j$ are given as

$$
A_{i i}^{(p)}=-\sum_{j=1, j \neq i}^{N} A_{i j}^{(p)} ; \quad p=1 \text { or } 2 ; \text { and for } i=1,2, \ldots, N,
$$

The weighting coefficient of the third and fourth order derivatives can be computed easily from $A_{i j}$ and $B_{i j}$ by

$$
C_{i j}=\sum_{k=1}^{N} A_{i k} B_{k j}, \quad D_{i j}=\sum_{k=1}^{N} B_{i k} B_{k j} .
$$

Two different types of sampling grids are taken into consideration in this study. A natural, and often convenient, choice for sampling points is that of equally spaced grid (ES-G) points. These points are given by,

Type-I: $x_{i}=\frac{i-1}{N_{x}-1}$ and $y_{i}=\frac{i-1}{N_{y}-1}$,

in the related directions. Sometimes, the DQ solutions deliver more accurate results with unequally spaced sampling points. Another choice that is found to be even better than the Chebyshev and Legendre polynomials is the set of points proposed by Shu and Richards [52]. These points are given as

Type-II: $\quad x_{i}=\frac{1}{2}\left[1-\cos \left(\frac{2 i-1}{N_{x}-1}\right) \pi\right] ;$ and $\quad y_{i}=\frac{1}{2}\left[1-\cos \left(\frac{2 i-1}{N_{y}-1}\right) \pi\right]$.

in the $x$ - and $y$-directions, respectively. These type grid points are known the ChebyshevGauss-Lobatto or non-equally spaced grid (NES-G) points. The displacement terms are taken as

$$
\begin{aligned}
& u=U(x) \cdot \cos (n \theta) \cdot \cos (\varpi t), \\
& v=V(x) \cdot \sin (n \theta) \cdot \cos (\varpi t), \\
& w=W(x) \cdot \cos (n \theta) \cdot \cos (\varpi t) .
\end{aligned}
$$

where $\varpi$ is referred to as the frequency parameter. Substituting Equations (14) into Equations (1), the governing equations can be written as

$$
\left[G_{i j}\right]\{D\}=0
$$


In this study, the numerical results are given by the dimensionless frequency parameter $\Omega$, defined as

$$
\Omega=R_{2} \sqrt{\frac{\rho h}{A_{11}}} \varpi .
$$

\section{Numerical results}

Some results have been presented for rotating and non-rotating shells. Firstly, frequency values for non-rotating shells have been presented in Table 1. The results produced by DSC and DQ are close agreement with the literatures. In this study, we used the classical shell theory. The differences amongst the results occurred from the different shell theory between this study and literature results (3-D elasticity and FSDT). Secondly, the effect of thickness on frequency for rotating shells is investigated and results presented in Table 2. Both the DSC and DQ produced very good results for 11 grid numbers. When we increase the same rate of thickness and length the frequency decreased interestingly. The results depicted in Fig. 2. For this graph the following values have been used : $E=68.2 \mathrm{GPa}, \rho=2700 \mathrm{~kg} / \mathrm{m}^{3}, \mathrm{v}=0.33$, $\mathrm{L}=1.7272 \mathrm{~m}, \mathrm{R}=0.0762 \mathrm{~m}, \mathrm{~h}=0.00147 \mathrm{~m}$. The results obtained via ANSYS packed programs.

Table 1 . Frequency parameters of $S-S$ cylindrical shells $(\mathrm{h} / \mathrm{R}=0.05 ; \mathrm{R} / \mathrm{L}=0.05 ; \mathrm{m}=1)$

\begin{tabular}{ccccc}
\hline $\mathrm{n}$ & Ref.6 & Ref.7 & $\begin{array}{c}\text { Present } \\
\text { DSC }\end{array}$ & $\begin{array}{c}\text { Present } \\
\text { DQ }\end{array}$ \\
\hline 2 & 0.039233 & 0.039819 & 0.039317 & 0.039319 \\
\hline 3 & 0.109477 & 0.109898 & 0.109620 & 0.109621 \\
\hline 4 & 0.209008 & 0.210310 & 0.209975 & 0.209978 \\
\hline
\end{tabular}

Table 2. Frequency values $\left(\Omega=\omega R \sqrt{\rho\left(1-v^{2}\right) / E}\right.$ ) of rotating isotropic cylindrical shells $(\mathrm{L} / \mathrm{R}=10 ; \mathrm{v}=0.3 ; \lambda=0.005 \mathrm{rps})$ with $\mathrm{C}-\mathrm{C}$ boundary conditions

\begin{tabular}{ccccc}
\hline & \multicolumn{2}{c}{$\begin{array}{c}\text { Present DSC Result } \\
(11 \times 11)\end{array}$} & \multicolumn{2}{c}{$\begin{array}{c}\text { Present DQ Result } \\
11 \times 11\end{array}$} \\
\hline $\begin{array}{c}\text { Mode } \\
\text { numbers }\end{array}$ & $\mathrm{h} / \mathrm{R}=0.02$ & $\mathrm{~h} / \mathrm{R}=0.05$ & $\mathrm{~h} / \mathrm{R}=0.02$ & $\mathrm{~h} / \mathrm{R}=0.05$ \\
\hline 2 & 0.04133 & 0.05409 & 0.04134 & 0.05409 \\
3 & 0.04769 & 0.11043 & 0.04772 & 0.11043 \\
4 & 0.08143 & 0.21003 & 0.08148 & 0.21001 \\
\hline
\end{tabular}




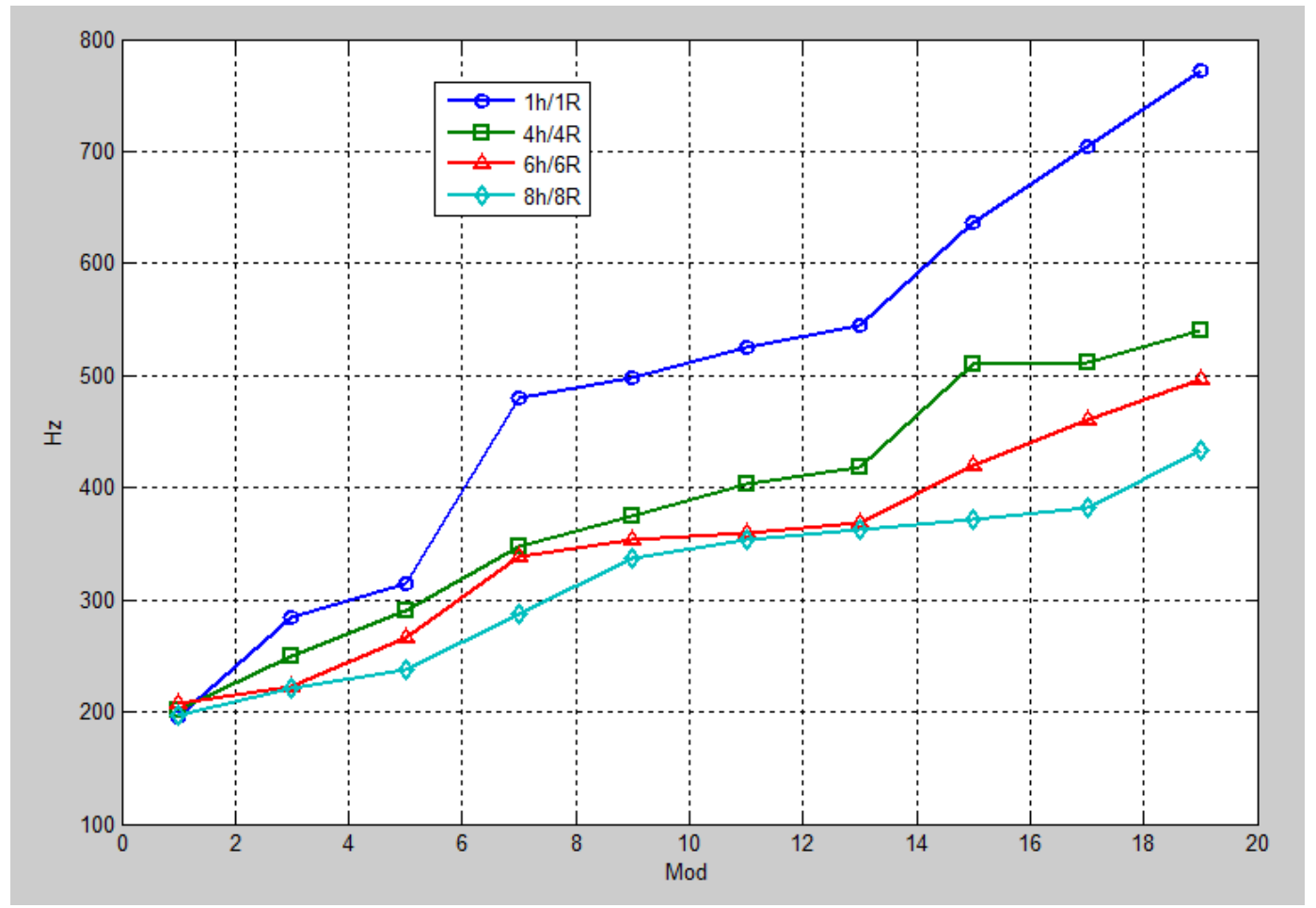

Fig. 2. The effect of thickness on frequency

\section{Conclusions}

It is shown that, the method of DSC and DQ have capable to give accurate results for rotating or non-rotating shells. The effect of other parameters on frequency have also been under consideration and published in the next.

\section{Acknowledgements}

The financial support of the Scientific Research Projects Unit of Akdeniz University is gratefully acknowledged.

\section{References}

[1] Bert, C.W., Baker, J.L., and Egle, D.M., Free vibration of multilayered anisotropic cylindrical shells, Journal of composite materials, 3, 480-499, 1969.

[2] Dong, S.B., Free vibration of laminated orthotropic cylindrical shells, Journal of Acoustical Society of America, 44, 1628-1635, 1968.

[3] Lam, K.Y., Loy, C.T., Analysis of rotating laminated cylindrical shells by different shell theories, Journal of Sound and Vibration, 186(1), 23-35, 1995.

[4] Hua, L., Frequency characteristics of a rotating truncated circular layered conical shell, Composite structures, 50, 59-68, 2000.

[5] Hua, L., Lam, K.Y., Frequency characteristics of a thin rotating cylindrical shell using the generalized differential quadrature method, International Journal of Mechanical Sciences, 40(5),443-459, 1998. 
[6] Chung, H., Free vibration analysis of circular cylindrical shells, Journal of Sound and Vibration, 74,331-350, 1981.

[7] Dym, C.L., Some new results for the vibrations of circular cylinders, Journal of Sound and Vibration, 29,189-205, 1973.

[8] Smith, B.L., Haft, E.E., Natural frequencies of clamped cylindrical shells, Journal of Aeronautics and Astronautics, 6, 720-721, 1968.

[9] Liew, K.M., Ng., T.Y., Zhao, X., and Reddy, J.N., Harmonic reproducing kernel particle method for free vibration analysis of rotating cylindrical shells, Computer Methods in Applied Mechanics and Engineering, 191, 4141-4157, 2002.

[10] Soldatos, K.P., A comparison of some shell theories used for the dynamic analysis of cross-ply laminated circular cylindrical panels, Journal of sound and vibration, 97, 305-319, 1984.

[11] Lam, K.Y., Loy, C.T., Influence of boundary conditions for a thin laminated rotating cylindrical shell, Composite Structures, 41, 215-228, 1998.

[12] Love A.E.H., A Treatise on the Mathematical Theory of Elasticity, Cambridge Unviersity Press, Cambridge, 1952.

[13] Wei G.W., Discrete singular convolution for the solution of the Fokker-Planck equations. The Journal of chemical physics, 110:8930 -8942, 1999.

[14] Wei, G.W., Zhou Y.C., Xiang, Y., A novel approach for the analysis of highfrequency vibrations, Journal of Sound and Vibration, 257(2), 207-246, 2002.

[15] Wei G.W., A new algorithm for solving some mechanical problems, Computer Methods in Applied Mechanics and Engineering, 190,2017-2030, 2001.

[16] Wei, G.W., Vibration analysis by discrete singular convolution, Journal of Sound and Vibration, 244, 535-553, 2001.

[17] Wei, G.W., Discrete singular convolution for beam analysis, Engineering Structures, 23, 1045-1053, 2001.

[18] Wei, G.W., Zhou Y.C., Xiang, Y., Discrete singular convolution and its application to the analysis of plates with internal supports. Part 1: Theory and algorithm. International Journal for Numerical Methods in Engineering, 55,913-946, 2002.

[19] Wei, G.W., Zhou Y.C., Xiang, Y., The determination of natural frequencies of rectangular plates with mixed boundary conditions by discrete singular convolution, International Journal of Mechanical Sciences, 43,1731-1746, 2001.

[20] Zhao, Y.B., Wei, G.W. and Xiang, Y., Discrete singular convolution for the prediction of high frequency vibration of plates, International Journal of Solids and Structures, 39, 65-88, 2002.

[21] Zhao, Y.B., and Wei, G.W., DSC analysis of rectangular plates with non-uniform boundary conditions, Journal of Sound and Vibration, 255(2), 203-228, 2002.

[22] Hou, Y., G. W. Wei and Y. Xiang, DSC-Ritz method for the free vibration analysis of Mindlin plates, International Journal for Numerical Methods in Engineering, 62,262288, 2005.

[23] Lim, C.W., Li Z. R., and Wei, G. W., DSC-Ritz method for high-mode frequency analysis of thick shallow shells, International Journal for Numerical Methods in Engineering, 62, 205-232, 2005. 
[24] Lim, C.W., Li, Z.R., Xiang, Y., Wei, G.W. and Wang, C.M., On the missing modes when using the exact frequency relationship between Kirchhoff and Mindlin plates, Advances in Vibration Engineering, 4, 221-248, 2005.

[25] Civalek, Ö., An efficient method for free vibration analysis of rotating truncated conical shells, International Journal of Pressure Vessels and Piping, 83, 1-12, 2006.

[26] Civalek, Ö., The determination of frequencies of laminated conical shells via the discrete singular convolution method, Journal of Mechanics of Materials and Structures, 1(1), 163-182, 2006.

[27] Civalek, Ö., Free vibration analysis of single isotropic and laminated composite conical shells using the discrete singular convolution algorithm, Steel and Composite Structures, 6(4),353-366, 2006.

[28] Civalek, Ö., Three-dimensional vibration, buckling and bending analyses of thick rectangular plates based on discrete singular convolution method, International Journal of Mechanical Sciences, 49, 752-765, 2007.

[29] Civalek, Ö., A four-node discrete singular convolution for geometric transformation and its application to numerical solution of vibration problem of arbitrary straightsided quadrilateral plates, Applied Mathematical Modelling, 33(1), 300-314, 2009.

[30] Civalek, Ö., Vibration Analysis of Laminated Composite Conical Shells by the Method of Discrete Singular Convolution Based on the Shear Deformation Theory, Composite Part-B: Engineering, 451001-1009, 2013.

[31] Civalek, Ö., Analysis of thick rectangular plates with symmetric cross-ply laminates based on first-order shear deformation theory, Journal of Composite Materials, 42(26), 2853-2867, 2008.

[32] Civalek, Ö., Free vibration analysis of symmetrically laminated composite plates with first-order shear deformation theory (FSDT) by discrete singular convolution method, Finite Elements in Analysis and Design, 44(12-13)725-731, 2008.

[33] Civalek, Ö., Vibration analysis of conical panels using the method of discrete singular convolution, Communications in Numerical Methods in Engineering, 24, 169-181, 2008.

[34] Civalek, Ö., Gürses, M., Free vibration analysis of rotating cylindrical shells using discrete singular convolution technique, International Journal of Pressure Vessels and Piping, 86, 677-683, 2009.

[35] Civalek, Ö., Fundamental frequency of isotropic and orthotropic rectangular plates with linearly varying thickness by discrete singular convolution method, Applied Mathematical Modelling, 33(10), 3825-3835, 2009.

[36] Baltacioglu, A.K., Civalek, Ö., Akgöz, B., Demir, F., Large deflection analysis of laminated composite plates resting on nonlinear elastic foundations by the method of discrete singular convolution. International Journal of Pressure Vessels and Piping, 88, 290-300, 2011.

[37] Civalek, Ö., Free vibration and buckling analyses of composite plates with straightsided quadrilateral domain based on DSC approach, Finite Elements in Analysis and Design,43,1013-1022, 2007. 
[38] Civalek, Ö., Korkmaz, A.K., Demir, Ç., Discrete Singular Convolution Approach for Buckling Analysis of Rectangular Kirchhoff Plates Subjected to Compressive Loads on Two Opposite Edges, Advance in Engineering Software, 41, 557-560, 2010.

[39] Civalek, Ö., Finite Element analysis of plates and shells, Elazı̆̆, Firat University,(in Turkish), Seminar Manuscript, 1998.

[40] Markus, S., The mechanics of vibrations of cylindrical shells, Elsevier, New York, 1988.

[41] Li, H., Lam, K.Y., Frequency characteristics of a thin rotating cylindrical shell using the generalized differential quadrature method, International Journal of Mechanical Sciences, 40, 443-459, 1998.

[42] Zhang, L. Xiang Y., and Wei, G.W., Vibration analysis of cylindrical shells by a local adaptive differential quadrature method, International Journal Mechanics and Science, 48(10), 1126-1138, 2006.

[43] Liew, K.M., Han, J-B., Xiao, Z.M., and Du, H., Differential quadrature method for Mindlin plates on Winkler foundations, International Journal of Mechanical Sciences 38(4), 405-421, 1996.

[44] Bert, C.W., Wang, Z. and Striz, A.G., Differential quadrature for static and free vibration analysis of anisotropic plates, International Journal of Solids and Structures 30(13), 1737-1744, 1993.

[45] Bert, C.W. and Malik, M., Free vibration analysis of tapered rectangular plates by differential quadrature method: a semi- analytical approach, Journal of Sound and Vibration 190(1), 41-63, 1996.

[46] Bert, C.W. and Malik, M., Differential quadrature method in computational mechanics: a review, Applied Mechanics Review, 49(1), 1-28, 1996.

[47] Civalek, Ö., Ülker, M., HDQ-FD Integrated Methodology For Nonlinear Static and Dynamic Response of Doubly Curved Shallow Shells, International Journal of Structural Engineering and Mechanics, 19(5), 535-550, 2005.

[48] Civalek, Ö., Demir, Ç., Bending analysis of microtubules using nonlocal EulerBernoulli beam theory, Applied Mathematical Modelling, 35(5)2053-2067, 2011.

[49] Civalek, Ö., Geometrically nonlinear dynamic and static analysis of shallow spherical shell resting on two-parameters elastic foundations, International Journal of Pressure Vessels and Piping, 113, 1-9, 2014.

[50] Civalek, Ö., Çok Serbestlik Dereceli Sistemlerin Harmonik Diferansiyel Quadrature (HDQ) Metodu ile Lineer ve Lineer Olmayan Dinamik Analizi, Dokuz Eylül Üniversitesi Fen Bilimleri Enstitüsü, 2003.

[51] Liew, K.M., Teo T.M. and Han, J.B., Comparative accuracy of DQ and HDQ methods for three-dimensional vibration analysis of rectangular plates. International Journal for Numerical Methods in Engineering, 45, 1831-1848, 1999.

[52] Shu C. and Richards, B.E., Application of generalized differential quadrature to solve two-dimensional incompressible Navier-Stokes equations, International Journal for Numerical Methods in Fluids, 15, 791-798, 1992.

[53] Shu, C. and Xue, H., Explicit computations of weighting coefficients in the harmonic differential quadrature, Journal of Sound and Vibration, 204(3), 549-555, 1997. 
[54] Striz, A.G., Jang, S.K. and Bert, C.W., Nonlinear bending analysis of thin circular plates by differential quadrature, Thin-Walled Structures, 6, 51-62, 1988.

[55] Civalek, Ö., Application of differential quadrature (DQ) and harmonic differential quadrature (HDQ) for buckling analysis of thin isotropic plates and elastic columns, Engineering Structures, 26(2), 171-186, 2004.

[56] Civalek, Ö., and Ülker, M., Free vibration analysis of elastic beams using harmonic differential quadrature (HDQ), Mathematical and Computational Applications, 9(2), 257-264, 2004.

[57] Civalek, Ö., and Ülker, M., Harmonic differential quadrature (HDQ) for axisymmetric bending analysis of thin isotropic circular plates, International Journal of Structural Engineering and Mecanics, 17(1), 1-14, 2004.

[58] Civalek, Ö., Geometrically nonlinear dynamic analysis of doubly curved isotropic shells resting on elastic foundation by a combination of HDQ- FD methods, International Journal of Pressure Vessels and Piping, 82(6), 470-479, 2005.

[59] Civalek, Ö., Geometrically non-linear static and dynamic analysis of plates and shells resting on elastic foundation by the method of polynomial differential quadrature (PDQ), PhD. Thesis, Firat University, (in Turkish), Elazı̆̆ 2004.

[60] Mercan, K., Civalek, Ö., DSC method for buckling analysis of boron nitride nanotube (BNNT) surrounded by an elastic matrix, Composite Structures, 143, 300-309, 2016.

[61] Demir, Ç., Mercan, K., Civalek, Ö., Determination of critical buckling loads of isotropic, FGM and laminated truncated conical panel, Composites Part B: Engineering, 94, 1-10, 2016. 